\title{
ANALISIS TOTAL PRODUCTIVE MAINTENANCE PADA NEEDLE DETECTOR DIVISI PACKING
}

\author{
Nur Muchlisin ${ }^{1}$, Dian Janari ${ }^{2}$ \\ 1,2Program Studi Teknik Industri, Fakultas Teknologi Industri, Universitas Islam Indonesia \\ Jl. Kaliurang km. 14,5 Sleman, Yogyakarta 55584 \\ Email: nurmuchlisin93@gmail.com
}

\begin{abstract}
PT. Mataram Tunggal Garment is a company that produces clothes with 100\% of their production being exported to various countries. To maintain machine productivity, one of the factors to pay attention to is maintenance. This research focuses on needle detector conveyors in the packing division to determine the actual condition of the conveyors. Conveyor availability value in January is 100\%. In February the availability value decreased to $97.1 \%$ due to the conveyor breakdown with a frequency of 1 time. 6 hours of repair time required. For March, the availability value isin 100\% condition, which indicates the conveyor is in optimal condition. Suggestions for improvements that are proposed include improving technician skills to better understand the machine in question so that damage handling is faster. Recording every maintenance time is also very necessary to reduce the potential for damage to the machine considering that the longer the engine part is used, it will shrink. In addition to checking the part replacement process can be carried out if needed. Machine operators must understand theproper operation of the machine and perform maintenance independently.
\end{abstract}

Keywords: TPM; Needle Detector; Improvement

\begin{abstract}
ABSTRAK
PT. Mataram Tunggal Garment merupakan perusahaan yang memproduksi pakaian dengan $100 \%$ hasil produksi di ekspor ke berbagai negara.Untuk menjaga produktifitas mesin salah satu faktor yang diperhatikan adalah maintenance. Penelitian yang dilakukan berfokus pada konveyor needle detector yang berada pada divisi packing untuk mengetahui kondisi aktual konveyor. Nilai availability konveyor pada bulan Januari beradadalam kondisi 100\%. Pada bulan Februari nilai availability turun menjadi 97,1 \% yang diakibatkan oleh adanya breakdown konveyor dengan frekuensi 1 kali. Diperlukan waktu perbaikan selama 6 jam. Untuk bulan Maret nilai availability berada dalam kondisi 100\% yang menandakan konveyor berada pada kondisi yang optimal. Saran perbaikan yang diusulkan meliputi peningkatan skill teknisi agar lebih memahami mesin yang bersangkutan sehingga penanganan kerusakan menjadi lebih cepat. Pencatatan setiap kali maintenance juga sangat diperlukan untuk mengurangi potensi kerusakan mesin mengingat umur part mesin yang semakin lama digunakan akan mengalami penyusutan. Selain pengecekan dapat dilakukan proses penggantian part apabila diperlukan. Operator mesin harus memahami pengoperasian mesin denganbenar dan melakukan perawatan secara mandiri. Dengan peran proaktif seluruh elemen perusahaan maka konsep TPM akan semakin mudah diwujudkan sehingga produktifitas perusahaan tetap terjaga.
\end{abstract}

Kata Kunci: TPM; Jarum detector; Peningkatan

\section{PENDAHULUAN}

PT. Mataram Tunggal Garment merupakan perusahaan yang bergerak di bidang produksi pakaian yang sudah memiliki standar internasional karena hasil produknya 100\% diekspor ke mancanegara. Hampir setiap harinya perusahaan memproduksi pakaian dengan desain yangberbeda-beda dalam jumlah yang 
besar. Untuk itu perusahaan memiliki target-target yang harus dicapai setiap harinya. Hal ini memicu mesin produksi harus bekerja secara terus-menerus untuk mempertahankan produktifitas agar tetap terjaga.

Produktifitas didefinisikan sebagai hubungan antara barang atau jasa yang diproduksi dengan sumberdaya yang digunakan untuk memperoleh hasil (Nasution, 2016). Ahli lain berpendapat bahwa produktivitas adalah rasio totalitas ouput bagi totalitas input dalam periode tertentu(Sinungan, 2018). Dalam menjaga dan meningkatkan produktifitas salah satu faktor yang diperhatikan adalah maintenance fasilitas produksi. Maintenance adalah serangkaian kegiatan menjaga fasilitas dan peralatan berada dalam keadaan siap digunakan (Harsanto, 2013). Fasilitas dan peralatan produksi ini harus dipertahankan agar tetap dalam kondisi yang optimal. Apabila terjadi kerusakan, maka proses produksi akan terhambat dan lebih fatalnya jika mesin tidak berfungsi maka proses produksi tidak akan berjalan sama sekali. Masalah terhadap maintenance berkaitan erat dengan pencegahan kerusakan dan perbaikan kerusakan (Sudrajat, 2011).

Pada divisi packing PT. Mataram Tunggal Garment terdapat needle detector yang menggunakan fasilitas produksi atau mesin berupa konveyor. Needle detector berfungsi untuk mendeteksi adanya serpihan benda logam seperti patahan jarum dan juga kerikil. Setiap harinya ribuan pakaian jadi melewati konveyor ini sebelum nantinya dikemas kembali kedalam kardus sesuai dengan jenis pakaiannya. Untuk menjaga keandalan mesin diperlukan suatu konsep yang baik. Salah satu konsep untuk merealisasikan hal tersebut adalah Total Productive Maintenance (TPM). Total Productive Maintenance (TPM) merupakan suatu aktivitas perawatan yang mengikutsertakan semua elemen dari perusahaan, yang bertujuan untuk mencapai zero breakdown,zero defect, dan zero accident (Kurniawan, 2013). Definisi lain menjelaskan bahwa Total Productive Maintenance (TPM) adalah gambaran konsep untuk pemeliharan peralatan dan pabrikyang bertujuan untuk meningkatkan produktivitas serta meningkatkan kepuasan karyawan (Ansori \& Mustajib, 2013). Penelitian ini bertujuan untuk mengetahui performance maintenance yang diterapkan pada needle detector di PT. Mataram Tunggal Garment dengan menganalisa terjadinyabreakdown konveyor menggunakan konsep Total Productive Maintenance.

\section{METODE PENELITIAN}

\section{Jenis Penelitian}

Penelitian ini menggunakan metode kuantitatif. Penelitian kuantitatif didefinisikan sebagai metode penelitian yang dilandasi oleh filsafat positivisme, digunakan untuk meneliti sampel atau populasitertentu, pengumpulan data menggunakan instrument penelitian, analisis data bersifat kuantitatif atau statistik, yang bertujuan untuk menguji hipotesis yang telah ditetapkan (Sugiyono, 2017). Data yang digunakan berupa data record mesin perusahaan dengan beberapa parameter.

\section{Waktu dan Tempat Penelitian}

Penelitian ini dilaksanakan di PT. Mataram Tunggal Garment yang beralamat di Balong, Donoharjo, Ngaglik, Sleman, D.I. Yogyakarta selama 1 bulan pada periode 1 Desember - 31 Desember 2020.

\section{Target/Subjek Penelitian}

Subjek penelitian yang digunakan dalam metode interview adalah operator konveyor dan teknisi maintenance untuk memperoleh data record perusahaan serta metode observasi langsung yang dilakukan selama proses packing needle detector yang dilakukan oleh operator konveyor untuk mengetahui kondisi aktual di perusahaan.

\section{Prosedur Penelitian}

Prosedur yang ditempuh dalam penelitian ini adalah (1) identifikasi masalah, proses ini berupa penentuan latar belakang dan tujuan dari penelitian dilaksanakan; (2) perumusan masalah, acuan dalam penelitian ini berupa kajian literatur yang berkaitan dengan proses identifikasi masalah dankemudian dilakukan penentuan rumusan masalah yang ada di perusahaan; (3) tujuan penelitian, tahap selanjutnnya setelah perumusan masalah yang telah dibuat adalah menentukan tujuan penelitian yang berisi keinginan penulis untuk menganalisis dan memberikan saran perbaikan darimasalah yang terjadi di perusahaan; (4) 
batasan masalah, ruang lingkup penelitian akan masalah yang diteliti diberi batasan agar lebih fokus seperti tujuan awal penelitian.

\section{Data, Instrumen, dan Teknik Pengumpulan Data}

Penelitian ini menggunakan data primer dan data sekunder. Data primer adalah data yang diperoleh berdasarkan pengamatan langsung melalui interview yakni wawancara terhadap operator dan pihak yang berwenang serta observasi dengan cara mengamati secara langsung proses produksi yang menunjang pengambilan data yang diperlukan. Data yang digunakan dalam penelitian ini merupakan data berkenaan dengan mesin dan sistem perawatannya yang berupa data total operation time, downtime, dan frekuensi downtime. Selain data primer, penelitian inimenggunakan data sekunder yang diperoleh melalui kajian literatur yang berhubungan dengan permasalahan yang diangkat dalam penelitian.

\section{Teknik Analisis Data}

Teknik analisis data yang digunakan menggunakan pendekatan yang terdiri dari. Total Productive Maintenance merupakan suatu konsep yang bertujuan untuk memaksimalkan efektivitas fasilitas yang digunakan oleh perusahaan melalui kegiatan dan pemeliharaan yang terencana (Suzaki, 1987). Performance maintenance meliputi 3 bagian yaitu (Nakajima, 1988): (1) Reliability adalahkemungkinan peralatan dapat beroperasi dibawah keadaan normal dengan baik. Ahli lain berpendapat bahwa reliability adalah probabilitas sistem menginformasikan fungsi dalam waktu tertentu dalam kondisi operasi (Ebeling, 1997). Mean Time Between Failure (MTBF) adalah rata-rata waktu suatu mesin dapat dioperasikan sebelum terjadinya breakdown. MTBF didapat dari total waktu pengoperasian mesin dibagi dengan frekuensi kegagalan pengoperasian mesin karenabreakdown; (2) Maintainability adalah suatu usaha dan biaya untuk melakukan perawatan (pemeliharaan). Aktivitas maintainability dibagi menjadi 3 kelompok, yaitu preparation time, active maintenance time, dan delay time (O'Connor, 2001). Pengukuran dari maintainability adalah Mean Time To Repair (MTTR). Semakin tinggi hasil MTTR mengindikasikan rendahnya maintainability. MTTR juga merupakan indikator kemampuan (skill) dari operator maintenance mesin dalam mengatasi setiap masalah kerusakan. Dimana Breakdown Time adalah termasuk waktu menunggu untuk melakukan perbaikan atau repair. (3) Availability adalah proporsi waktu mesin yang sebenarnya tersedia dengan waktu yang ditargetkan untuk melakukan suatu pekerjaan.Diagram fishbone adalah diagram yang berbentuk seperti tulang ikan yang digunakan untuk mengidentifikasi penyebab masalah dan nantinya akan diketahui akar penyebab masalah tersebutterjadi (Baety, Budiasih, \& Atmaji, 2019). Ahli lain berpendapat diagram fishbone sebagai diagram yang menyerupai tulang ikan dimana setiap tulang mewakili kemungkinan sumber kesalahan (Heizer \& Render, 2014).

\section{HASIL PENELITIAN DAN PEMBAHASAN}

\section{Hasil Penelitian}

Dalam penelitian ini data record yang digunakan adalah selama periode Januari hingga Maret 2020. Data mengenai kerusakan konveyor disajikan sebagai berikut:

Tabel 1. Breakdown Konveyor

\begin{tabular}{cccc}
\hline No & Problem & Frekuensi & Downtime (jam) \\
\hline 1 & Pencatat jumlah pakaian tidak berfungsi/ & 1 & 6 \\
tidak bertambah & & \\
\hline
\end{tabular}


Tabel 2. Total Operation Time Konveyor

\begin{tabular}{|c|c|c|c|c|}
\hline \multirow[b]{2}{*}{ Periode } & \multirow{2}{*}{$\begin{array}{c}\text { Frekuensi } \\
\text { Breakdown }\end{array}$} & \multicolumn{2}{|c|}{ Total Operation Time } & \multirow[b]{2}{*}{ Total (menit) } \\
\hline & & Loading (mnt) & Breakdown(mnt) & \\
\hline Januari & 0 & 11.460 & 0 & 11.460 \\
\hline Februari & 1 & 12.300 & 360 & 11.940 \\
\hline Maret & 0 & 11.580 & 0 & 11.580 \\
\hline
\end{tabular}

\section{Pembahasan}

Selama tiga periode seperi pada tabel 1.1 dan 1.2, part yang mengalami kerusakan hanya pada pencatat jumlah yang error yaitu saat konveyor berjalan tidak bertambah sama sekali dengan frekuensi satu kali. Berikut merupakan hasil identifikasi penyebab kerusakan part seperti pada gambar 1.1 dan tabel 1.3 di bawah ini:

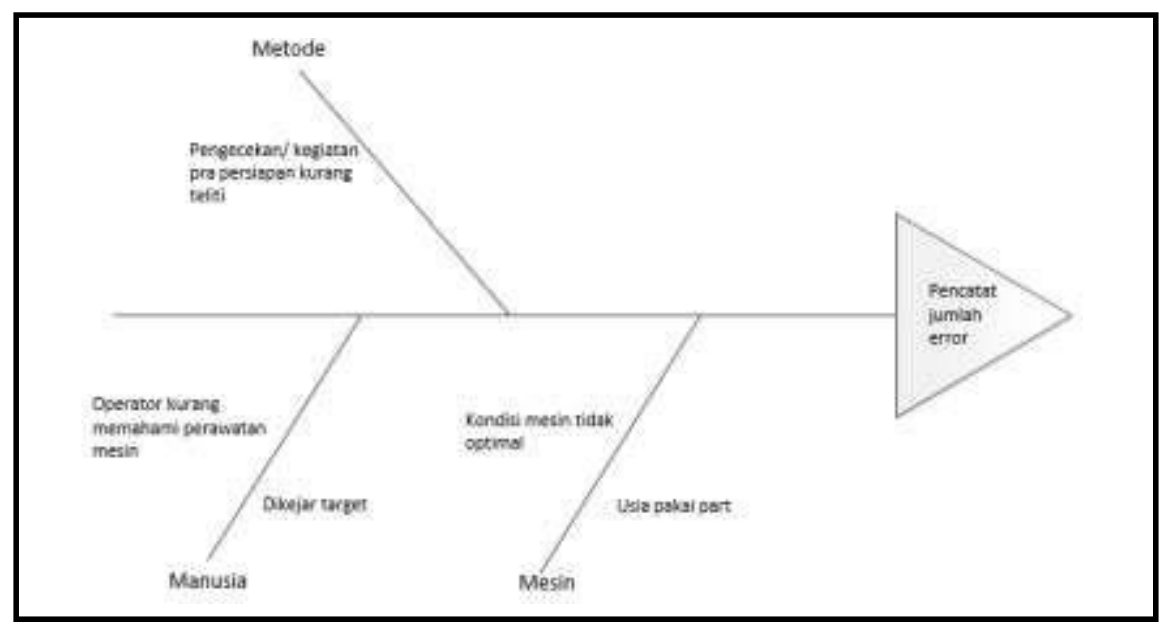

Gambar 1. Diagram Fishbone 
Tabel 3. Analisis Fishbone

\begin{tabular}{|c|c|c|c|}
\hline \multicolumn{2}{|c|}{ Faktor Penyebab } & Penyebab & Tindakan \\
\hline Mesin & $\begin{array}{l}\text { Kondisi mesin } \\
\text { tidak optimal }\end{array}$ & $\begin{array}{l}\text { Maintenance yang } \\
\text { kurang menyeluruh }\end{array}$ & $\begin{array}{l}\text { Dilakukan pengecekan dan } \\
\text { pengawasan secaraberkelanjutan }\end{array}$ \\
\hline \multirow{3}{*}{ Manusia } & Usia pakai part & $\begin{array}{l}\text { Usia pakai part yang } \\
\text { kurang diperhatikan } \\
\text { sehingga mengalami } \\
\text { penyusutan usiapakai }\end{array}$ & $\begin{array}{l}\text { Dilakukan pengecekan dan } \\
\text { penggantian part apabila diperlukan } \\
\text { untuk menjamin kelancaran proses }\end{array}$ \\
\hline & Target kerja & $\begin{array}{lr}\text { Target produksi } \\
\text { yang tinggi membuat } \\
\text { operator } & \text { menjadi } \\
\text { kurang fokus } & \text { ditambah } \\
\text { lingkungan } & \text { kerja } \\
\text { dengan kondisi } & \text { yang } \\
\text { cukup panas } & \end{array}$ & $\begin{array}{l}\text { Penambahan kegiatanrefreshing dan } \\
\text { menambah jumlah kipas untuk } \\
\text { mengurangi hawa panas }\end{array}$ \\
\hline & $\begin{array}{l}\text { Pemahaman } \\
\text { teknisi dan } \\
\text { operator mengenai } \\
\text { mesin kurang }\end{array}$ & $\begin{array}{l}\text { Kurangnya pengetahuan } \\
\text { yangberkaitan dengan } \\
\text { mesin sehingga } \\
\text { memerlukan waktu } \\
\text { lebih lama untuk } \\
\text { melakukan perbaikan }\end{array}$ & $\begin{array}{l}\text { Training yang diadakan perusahaan } \\
\text { dengan mendatangkan tenaga ahli } \\
\text { dengan menekankan jika } \\
\text { maintenance merupakan tanggung } \\
\text { jawab bersama. }\end{array}$ \\
\hline Metode & $\begin{array}{l}\text { Pengecekan yang } \\
\text { kurang teliti atau } \\
\text { menyeluruh }\end{array}$ & $\begin{array}{l}\text { Operator kurang } \\
\text { memahami penyetingan } \\
\text { konveyor }\end{array}$ & $\begin{array}{l}\text { Peningkatan softskill melalui training } \\
\text { yang dilakukan oleh perusahaan }\end{array}$ \\
\hline
\end{tabular}


Dari data yang sudah diperoleh seperti pada tabel 1.2 dilakukan pengolahan untuk mengetahui nilai MTBF, MTTR, dan Availability. Hasil pengolahan kemudian dianalisis untuk mengetahui permasalahan yang ada sehingga diketahui kondisi aktual performace maintenance pada konveyorneedle detector PT. Mataram Tunggal Garment. MTBF merupakan indikator keandalan mesin (reliability) yaitu waktu rata-rata antara breakdown dengan breakdown berikutnya. Hasil kumulatif untuk 3 periode adalah sebagai berikut:

Tabel 4. Hasil Perhitungan MTBF

\begin{tabular}{lcc}
\multicolumn{1}{c}{ Periode } & Menit & Jam \\
\hline Januari & 0 & 0 \\
Februari & 11.940 & 199 \\
Maret & 0 & 0 \\
\hline
\end{tabular}

Dari hasil perhitungan MTBF seperti pada tabel 1.4, dapat di ketahui bahwa pada bulan Januari keandalan mesin dikatakan baik karena tidak terjadi breakdown sama sekali. Untuk bulan Februariterjadi breakdown dengan frekuensi sebanyak satu kali. Hal ini membuat nilai MTBF pada bulan Februari menjadi lebih kecil atau dapat dikatakan mesin bekerja dalam kondisi di bawah optimal.Sebaliknya pada bulan Maret terjadi peningkatan MTBF, sehingga dapat disimpulkan bahwa tingkat keandalan konveyor dapat dikatakan baik.

MTTR merupakan waktu rata-rata yang digunakan untuk memperbaiki suatu kerusakan mesin/line. Hasil kumulatif untuk 3 periode adalah sebagai berikut :

Tabel 5. Hasil Perhitungan MTTR

\begin{tabular}{lcc}
\hline \multicolumn{1}{c}{ Periode } & Menit & Jam \\
\hline Januari & 0 & 0 \\
Februari & 360 & 6 \\
Maret & 0 & 0 \\
\hline
\end{tabular}

Dari hasil perhitungan seperti pada tabel diatas, pada bulan Februari terjadi kerusakan pada konveyor needle detector dengan frekuensi satu kali. Masalah yang terjadi adalah pencatat jumlahpakaian tidak berjalan atau berhenti sehingga konveyor tidak dioperasikan sama sekali mulai pukul 09.00 sampai pukul 15.00. Diperlukan waktu selama 6 jam untuk melakukan perbaikan hingga konveyor dapat dioperasikan kembali.

Availability adalah ratio untuk melihat kondisi mesin yang dilihat dari aspek breakdown saja. Hasil kumulatif untuk 3 periode adalah sebagai berikut : 
Tabel 6. Hasil Perhitungan Availability

\begin{tabular}{lc}
\hline \multicolumn{1}{c}{ Periode } & Availability \\
\hline Januari & $100 \%$ \\
Februari & $97,1 \%$ \\
Maret & $100 \%$ \\
\hline
\end{tabular}

Dari hasil perhitungan seperti pada tabel 6 menunjukkan bahwa ketersediaan mesin pada bulan Januari berada dalam kondisi 100\% sehingga kinerja konveyor dapat diandalkan atau dapatdikatakan dalam kondisi yang optimal. Namun pada bulan Februari terjadi penurunan nilai yang disebabkan oleh adanya kerusakan atau breakdown konveyor dengan frekuensi satu kali. Untuk periode berikutnya yaitu bulan Maret ketersediaan mesin berada dalam kondisi yang optimal, tentusaja ini merupakan hal yang baik karena produktifitas konveyor tetap terjaga tanpa adanya gangguan breakdown mesin.

Total Productive Maintenance merupakan konsep berkelanjutan yang didukung oleh kesadaran seluruh karyawan untuk menjaga performa mesin sehingga dapat meningkatkan produktifitas perusahaan. Hal ini juga akan berdampak pada laju sistem produksi perusahaan mengingat PT. Mataram Tunggal Garment harus mencapai target produksi untuk setiap kali pesanan yang diterima perusahaan. Apabila konsep TPM tidak berjalan dengan baik maka mesin akan sering mengalami kerusakan dan menghambat target produksi yang telah ditentukan perusahaan.

\section{KESIMPULAN}

Berdasarkan tujuan dan hasil penelitian yang dilakukan pada PT. Mataram Tunggal Garment dapat disimpulkan bahwa perusahaan perlu meningkatkan skill teknisi agar lebih memahami mesin yang bersangkutan sehingga penanganan kerusakan menjadi lebih cepat. Data record berupa catatan setiap kali maintenance juga sangat diperlukan untuk mengurangi potensi kerusakan mesinmengingat umur mesin yang semakin lama digunakan akan mengalami penyusutan fungsi. Untukitu selain dilakukan pengecekan secara berkala maka dapat dilakukan proses penggantian part apabila diperlukan ketika part tersebut sudah melebihi batas usia pakainya. Dalam operasinya, operator mesin harus memahami pengoperasian mesin dengan benar dan juga mampu melakukanperawatan mandiri dengan baik. Total Productive Maintenance yang diterapkan perusahaan pada konveyor needle detector berada dalam kondisi yang optimal dimana availability mesin berada dalam kondisi $100 \%$ denganhanya satu kali breakdown yaitu pada bulan Februari selama periode data record yang digunakanyaitu dari bulan Januari sampai Maret 2020. Hal tersebut menunjukkan produktifitas perusahaan berada dalam kondisi yang maksimal.

Penelitian terhadap perawatan mesin yang dilakukan perusahaan memberikan masukan yang dapat ditindaklanjuti antara seperti pentingnya peran atau partisipasi aktif seluruh karyawan didalamnyasangat diperlukan mengingat maintenance merupakan tanggung jawab bersama bukan hanya teknisi saja. Untuk penelitian selanjutnya dapat menambah objek penelitian agar hasil yang diperoleh dapat digunakan sebagai bahan evaluasi yang lebih menyeluruh.

\section{DAFTAR PUSTAKA}

Ansori, N., \& Mustajib, M. I. (2013). Sistem Perawatan Terpadu (Integrated Maintenance System). Yogyakarta: Graha Ilmu.

Baety, R., Budiasih, E., \& Atmaji, F. T. (2019). PENERAPAN TOTAL PRODUCTIVE MAINTENANCE (TPM) DALAM BOTTLENECK AUTO-PART MACHINING LINE MENGGUNAKAN METODE. e-Proceeding of Engineering, 6496-6505. 
Ebeling, C. E. (1997). An Introduction to Reliability and Maintainability. Singapore: TheMcGrawHill Companies, Inc.

Harsanto, B. (2013). Dasar Ilmu Manajemen Operasi. Bandung: Unpad Press.Heizer, \&

Render. (2014). Manajemen Operasi. Jakarta: Salemba Empat.

Nakajima, S. (1988). Introduction to TPM Total Productive Maintenance. Cambridge:Productivity Press, Inc.

Nasution, A. P. (2016). Effect of Leadership Style, Organizational Climate and Ethos of Work on Employee Poductivity (PT. HP Metals Indonesia the Powder Coating). International Journal of Business and Management, 1-5.

O'Connor, P. D. (2001). Practical Reliability Engineering, Fourth Edition. England: John Wiley \& Sons Ltd.

Sinungan, M. (2018). Produktivitas : Apa dan Bagaimana. Jakarta: Bumi Aksara.

Sudrajat, A. (2011). Pedoman Praktis Manajemen Perawatan Mesin Industri. Bandung: PT Refika Aditama.

Sugiyono. (2017). Metode Penelitian Kuantitatif, Kualitatif, dan R\&D. Bandung: CV Alfabeta.

Suzaki, K. (1987). Tantangan Industri Manufaktur : Penerapan Perbaikan. Jakarta: PQM. 